A Theory of Agricultural Marketing Cooperatives with Direct Selling

Maxime Agbo, Damien Rousselière, Julien Salanié

November 2013 


\section{GATE Groupe d'Analyse et de Théorie Économique Lyon-St Étienne}

93, chemin des Mouilles 69130 Ecully - France

Tel. +33(0)4 72866060

Fax $+33(0) 472866090$

6, rue Basse des Rives 42023 Saint-Etienne cedex 02 - France

Tel. +33 (0)4 77421960

Fax. +33 (0)4 77421950

Messagerie électronique / Email : gate@gate.cnrs.fr

Téléchargement / Download : http://www.gate.cnrs.fr - Publications / Working Papers 


\title{
A Theory of Agricultural Marketing Cooperatives with Direct Selling*
}

\author{
Maxime Agbo ${ }^{\dagger 1}$, Damien Rousselière ${ }^{\ddagger 1}$, and Julien Salanié ${ }^{\S} 2,3$ \\ ${ }^{1}$ Agrocampus-Ouest, Department of Economics, Management and Society, UMR GRANEM, France \\ ${ }^{2}$ Université de Lyon, Lyon, F-69007, France ; CNRS, GATE Lyon Saint-Étienne, Ecully, F-69130, \\ France \\ ${ }^{3}$ Université Jean Monnet, Saint-Etienne, F-42000, France
}

November 15, 2013

\begin{abstract}
We build a theoretical model to study a market structure of a marketing cooperative with direct selling, in which many farmers are members of an agricultural marketing cooperative. They can sell their production either to the cooperative or on a local market. We show that the decision to sell to the cooperative induces an anti-competitive effect on the direct selling market. Conversely, direct selling may create a "healthy emulation" among farmers, leading to more production benefiting the cooperative.
\end{abstract}

Keywords: marketing cooperative, direct selling, local market, competitive.

JEL Classifications: D43; L11; Q13.

${ }^{*}$ We thank Éric Avenel, Olivier Bonroy, Nérée Noumon, Stéphane Riou and Marc Santugini for their useful comments and Gemma Davies for her editorial assistance. Any remaining errors are our own. Financial support from Région Pays de la Loire (France) is gratefully acknowledged.

${ }^{\dagger}$ Corresponding author, Email: maxime.agbo@agrocampus-ouest.fr

${ }^{\ddagger}$ Email: damien.rousseliere@agrocampus-ouest.fr

${ }^{\S}$ Email: julien.salanie@univ-st-etienne.fr 


\section{Introduction}

In this paper, we investigate a market structure in which firms simultaneously compete and cooperate with each other. This is specifically the case of farmers around the world who are increasingly encouraged to join marketing cooperatives in order to sell their products and open up opportunities for direct, local market selling.

Cooperatives play an important role and hold a significant market share in agricultural product distribution from farms to final consumers (Deller et al., 2009). For example, according to a publication by the International Labour Office, more than $50 \%$ of global agricultural output is marketed through cooperatives in Finland, Italy, and the Netherlands (Tchami, 2007). In 2002, agricultural cooperatives accounted for $27 \%$ of U.S. total farm marketing expenditure (USDA, 2004). Marketing cooperatives comprise about $53 \%$ of all cooperatives and product distribution represents $64 \%$ of the net business volume of cooperatives in the U.S. (USDA, 2011). The rationale is that marketing cooperatives allow small farmers to get better, or rather a secured, price by overcoming the "powerful" oligopsonist Investor-owned firms (IOFs) (Sexton, 1990, Bontems \& Fulton, 2009). With marketing cooperatives, farmers have a much better potition for price negocation (Ladd, 1974, Cakir \& Balagtas, 2012) and open up access to markets that they cannot access individually (Camanzi et al. 2011). Cooperatives also enable farmers to face uncertainty about agricultural market prices (Jang \& Klein, 2011).

Meanwhile, there is a growing trend towards direct selling (Brown \& Miller, 2008, Timmons \& Wang, 2010, Uematsu \& Mishra, 2011; Low \& Vogel, 2011; Fischer \& Qaim, 2012). In direct selling, consumers purchase cut out the middleman by purchasing directly from farmers. As reported by Timmons \& Wang (2010), direct food sales from farmers to consumers in the U.S. increased by $59 \%$ from 1997 to 2007 . In 2010 , more than $21 \%$ of french producers were involved in direct selling 11 Unlike cooperatives, and depending on the market conditions, with direct selling the farmer has control over sales prices and therefore obtain greater market power. This enables farmers to increase their profit margin (Uematsu \& Mishra, 2011) 2 In practice, many farmers combine direct selling and marketing through cooperatives. They sell part of their production to the cooperative and the rest is sold directly to the consumers. For example in France, 19.5\% of apple producers, who are members of a cooperative, sell via these cooperatives and at the same time directly on local markets. For pear producers however, this proportion falls to $15 \% \mathrm{~S}^{3}$

On the other hand, direct selling is a serious concern for some marketing cooperatives managers. Indeed, in a context where membership and loyalty are threatened (USDA, 2002, Bond, 2006, Bijman \& Verhees, 2011; Mujawamariya et al., 2013), cooperatives increasingly question the pertinence of allowing their members to sell directly to consumers. Specifically, marketing cooperatives fear that they may not be able sustain the stock required for their activity if members are engaged in direct selling. To avoid collapse, some cooperatives prevent their members from selling through other channels than the cooperative, or settle (with mem-

\footnotetext{
${ }^{1}$ Source: Census of Agriculture, French Department of Agriculture, 2007.

${ }^{2}$ According to Jang \& Klein (2011), small farmers often sell their products directly to consumers for a greater price than wholesale.

${ }^{3}$ Source: Authors calculations based on the Orchard Survey, French Department of Agriculture, 2007.
} 
bers) contracts which guarantee a minimum volume of delivery. For instance in France, all of the milk production from dairy cooperative members must go through the cooperative, while in the U.S. tobacco marketing cooperatives allow farmers to draw up contracts to distribute their production through other channels 4 In other words, the acceptability of direct selling is not self-evident.

The purpose of this paper is to study the market structure generated by the sale of goods simultaneously through cooperatives and directly to consumers. Indeed, the framework of a marketing cooperative coupled with direct selling describes a specific environment and market structure. In many situations, farmers sell directly to consumers on local markets avoiding transaction costs (Timmons \& Wang, 2010). On the local market, farmers make decisions independently which may lead to competition between each other. Another point to consider is that the local market generally differs from the market where the cooperative operates ${ }^{5}$ Therefore, for farmers, the market is composed of two parts. The first is the market on which the marketing cooperative sells the volume of production proposed by farmers. On this market, farmers sell collectively and cooperatively. The second is the direct local market selling where farmers are in oligopoly. The first goal of this paper is to analyze behaviors in the specific market structure where farmers are on the one hand in cooperation and in oligopolistic competition on the other. We study how they share their production between the two distribution channels, and the interdependence between the two 6 Our second goal is to revisit cooperative managers' concerns and see how direct selling could be beneficial for marketing cooperatives.

We build a model in which a marketing cooperative is owned by many farmers who produce a homogeneous good. They have the possibility to sell their production either to the cooperative or on a local market. The cooperative sells farmers' goods on a large competitive market where the price can not be negociated. In addition to the marketing cooperative, farmers have access to a local market where they can sell directly to consumers. We assume that the large competitive market and the local market are separated, and the local market is oligopolistic. The marketing cooperative does not control farmers' production decisions, but decides the price at which it buys the goods from farmers. In turn, farmers decide on the production quantity and how to share this production between the local market and the cooperative.

Our analysis stresses three important results. First, we find that, under certain conditions, farmers sell the same quantity on local market, even though they do not produce the same amount of product. Farmers behave as if they collude together concerning quantities destined for the local market, limiting competition, in order to get a higher price for their goods. Compared to the standard oligopolistic structure, the presence of the marketing cooperative allows farmers to reduce the amount of product sold on the local market, hence reducing

\footnotetext{
${ }^{4}$ We can also mention the example of New Generation Cooperatives (Cook \& Chaddad, 2004, Holland \& King, 2004).

${ }^{5}$ For example in some developing countries, the quantity of cocoa, coffee, cotton, pineapple, among others marketed through cooperatives are exported. The rest of the production is sold directly by farmers to local processors, final consumers, etc.

${ }^{6}$ In previous literature, economists mostly focused on the case where the two possibilities are marketing cooperatives and IOFs. In that literature, marketing cooperatives compete against IOFs (Sexton, 1990, Tennbakk, 1995. Giannakas \& Fulton, 2005). But in our case, the challenge for the cooperative is its own members.
} 
competition on that particular market. Since they have at their disposal the opportunity to sell through the cooperative (where they are not in competition), they seek to preserve a higher price on the local market. We show that an increase in the number of farmers increases the share of aggregate production delivered to the cooperative. Even though the cooperative does not have market power in our model, it enables farmers to strengthen their market power on the local market. Thus, the marketing cooperative plays an important role in the local market performance. Farmers' decision to sell to the cooperative depends on the local market demand, the price on the large competitive market, farmers' efficiency, and the number of farmers.

Second, we also find that, compared to a situation in which farmers do not have direct selling opportunity, farmers deliver more to the cooperative if the maximal possible price on local market is lower than the price on the large competitive market. Since direct selling is operated on oligopolistic market, it brings more competitive structure to the model. In other words, direct selling through oligopolistic market creates a "healthy emulation", and incites farmers to produce more. But if the local demand is not sufficient enough to preserve higher local price, this production surplus will go to the cooperative. In other words, direct selling is not necessarily harmful for cooperatives.

The third main result concerns the case where the marketing cooperative and farmers are selling on the same local market. We find that the two channels of distribution cannot coexist. If the cooperative is able to purchase the goods from the farmers at a price above the market price, then all the production is delivered to the cooperative. Such a situation could happen if, for instance, the cooperative receives subsidies from institutions outside the market, like for example the government. In contrast, if the cooperative cannot set its purchase price above the market price, farmers will sell all their produce directly.

The rest of the paper is organized as follows. We present the model and derive optimal behaviors respectively in Sections 2 and 3 . Sections 4 and 5 analyze the interdependence between direct selling performance and marketing cooperative. In Section 6, we discuss the specific case where the marketing cooperative and farmers are operating on the same market. We conclude in Section 7 .

\section{The Model}

In this section, we present our model which is the hybrid case of the marketing cooperative with direct selling. But before presenting the model, we introduce two benchmark models, which are the two extreme cases of full marketing cooperative where the farmers have to deliver their whole production to the cooperative, and of full direct selling where farmers are not members of a cooperative and sell their products themselves on a local market. These two benchmark models are used to study how the marketing cooperative with direct selling affects agents' behavior. We also derive the quantity produced by the farmers for each benchmark. 


\subsection{Marketing cooperative with no direct selling: full marketing coopera- tive}

Consider an agricultural marketing cooperative owned by $N \geq 2$ farmers. The farmers produce a homogeneous product and sell it to the cooperative at a unit price $p_{c}$. Farmer $i$ decides and produces the good in quantity of $q_{i}$ at a total cost of $C_{i}\left(q_{i}\right)=A_{i} q_{i}^{2}$, where $A_{i}$ is a positive constant $7^{7}$ In turn the cooperative sells the product on a large competitive market at a unit price $P$. Here, we abstract from any processing and distribution costs borne by the cooperative. We assume that the product delivered by farmers is sold by the cooperative without being processed (example of fruits and vegetable, eggs, ..., as in Tennbakk (1995)). We also assume that the cooperative takes the price $P$ as given, but decides on the price $p_{c}$ to buy the product from the farmers 8 We consider the cooperative does not price discriminate and proposes the same unit price to all members 9 . Therefore, the profit of the cooperative is

$$
\pi_{c}=\left(P-p_{c}\right) \sum_{j=1}^{N} q_{j}
$$

As owner of the cooperative, each farmer receives a percentage $b_{c} \leq \frac{1}{N}$ of the profit made by the cooperative (Karantininis \& Zago, 2001) 10 So, the total profit of the producer $i$ is

$$
u_{i}=p_{c} q_{i}-A_{i} q_{i}^{2}+b_{c} \pi_{c}
$$

The game is as follows. Given the market price $P$, the cooperative chooses the price $p_{c}$ that maximizes its profit $\pi_{c}$. Each farmer $i$, leaning on $p_{c}$, choose the quantity $q_{i}$ to produce and to sell to the cooperative, by maximizing his profit $u_{i}$.

Unlike an investor-owned firm (IOF), the cooperative's profit maximizing is also beneficial for the members, as a part of the profit is returned to them. Moreover, profit maximization by the cooperative does not necessarily consist of paying farmers a low price for goods. In order to encourage delivering, the cooperative has to decide on a reasonable price $p_{c}$. In other words, the problem of the cooperative is to choose a price $p_{c}$ that insures its supplying, while maximizing the cooperation return to farmers. This consideration is similar to the seminal work by Helmberger \& Hoos (1962).

\footnotetext{
${ }^{7}$ In other words, the cooperative's managers do not have control over farmers' output, as in Karantininis \& Zago (2001), Albaek \& Schultz (1998).

${ }^{\circ}$ For models in which cooperatives are price-takers in their selling market, see Karantininis \& Zago (2001), Albaek \& Schultz (1997), Sexton (1990).

${ }^{9}$ In our case of homogeneous product, there is no reason to consider a price discriminating cooperative. For papers considering unique price for all farmers, see for example Albaek \& Schultz (1997), Royer \& Matthey (1999), Giannakas \& Fulton (2005). However, a cooperative can price discriminate farmers if there are heterogenous products of different qualities (Hendrikse \& Bijman, 2002, Pascucci et al., 2012).

${ }^{10}$ Here, we assume that the farmers receive an equal part of the cooperative's profit, as done in Tennbakk (1995). We could consider that the profit is shared proportionally to the quantity delivered by the farmer. Specifically, farmer $i$ receives a part $q_{i} / \sum q_{j}$ (like investment sharing in cooperatives, as in Albaek \& Schultz (1997)). Therefore, the profit of farmer $i$ is $u_{i}=p_{c} q_{i}-A_{i} q_{i}^{2}+\mu \pi_{c}\left(q_{i} / \sum q_{j}\right)=p_{c} q_{i}-A_{i} q_{i}^{2}+\mu\left(P-p_{c}\right) q_{i}$, where $0<\mu<1$ is the part of the profit the cooperative decides to share out. However, as it is easy to check, considering proportionally profit sharing would not change our results. We do a short discussion in footnote 15. See also Fatas et al. (2010) for other view on benefits sharing in cooperatives.
} 
The first-order condition of the farmer $i$ yields

$$
q_{i}=\frac{b_{c} P+\left(1-b_{c}\right) p_{c}}{2 A_{i}}
$$

Using (3) the cooperative's problem becomes ${ }^{11}$

$$
\max _{p_{c}}\left(P-p_{c}\right)\left(b_{c} P+\left(1-b_{c}\right) p_{c}\right) \sum_{j=1}^{N} \frac{1}{2 A_{i}}
$$

Solving the problem in (4) gives the optimal price and quantity

$$
\hat{p}_{c}=\frac{\left(1-2 b_{c}\right) P}{2\left(1-b_{c}\right)} \quad \text { and } \quad \hat{q}_{i}=\frac{P}{4 A_{i}}
$$

One could remark that the farmers' decision does not depend on $b_{c}$, the part of the profit received as owners. Actually, when making their production and delivering decision, the farmers are more interested in the price they will be paid, as this price relies on the large competitive price $P$. On the other hand, this result is also a consequence of the traditional agricultural cooperatives' characteristics, which is what makes them different from investorowned firms (IOFs). There is a trade-off between the price $p_{c}$ paid by the cooperative and the profit share $b_{c}$. Deriving the equilibrium price $p_{c}$ in 5 yields $\frac{\partial \widehat{p_{c}}}{\partial b_{c}} \leq 0$. Farmers are owners, controllers, and beneficiaries of the cooperative (Bijman et al., 2013). If for instance $b_{c}$ decreases because of an increase of reserves, farmers (as beneficiaries) will benefit from that increase of reserves, even though they bear a loss as owners. If $b_{c}$ decreases for other reasons, as controllers the members can increase $p_{c}$ to compensate. In other words, the cooperative adjusts the price $p_{c}$ to $b_{c}$. So, only market conditions and their production efficiency matter to farmers. Therefore, in order to succeed in preserving membership, agricultural cooperatives either need to reinforce their market power or help farmers improve their production efficiency. Another result worth mentioning is that, unlike Albaek \& Schultz (1998), the individual production does not depend on the number of farmers. This is because the cooperative does not have market power and operates on a competitive market.

\subsection{Direct selling without marketing cooperative: full direct selling}

Consider $N$ farmers $(N \geq 2)$ producing a homogeneous agricultural good that they sell to final consumers on a local market 12 We assume that the local market is an oligopolistic one, where the consumers demand for the agricultural good is characterized by the inverse-demand

\footnotetext{
${ }^{11}$ We consider that the cooperative maximizes its profit as considered in Hoffmann (2005), Lopez \& Spreen (1985), Royer \& Matthey (1999), Hovelaque et al. (2009). Boyle (2004) found empirical evidences that cooperatives behave as if they are profit maximizers. However, some authors considered a members-welfare-maximizing cooperative (Giannakas \& Fulton, 2005, Tennbakk, 1995, Sexton, 1986). Actually, as mentioned by Tennbakk (1995), there is no consensus regarding what cooperatives maximize. See Soboh et al. (2009) for more complete review on the objective functions of cooperatives.

${ }^{12}$ The definition of "local" is an ongoing debate in the literature (Hand \& Martinez, 2010). In this paper, the market is local when farmers and consumers have access with negligible transaction costs (mostly transportation cost).
} 
function $P^{o}=\alpha-\beta Q^{o}, Q^{o}$ being the total production of all the farmers. Farmer $i$ chooses the quantity $q_{i}^{o}$ to produce by maximizing his profit defined as

$$
V_{i}^{o}=\left(\alpha-\beta \sum_{j=1}^{N} q_{j}^{o}\right) q_{i}^{o}-A_{i}\left(q_{i}^{o}\right)^{2},
$$

where $A_{i}\left(q_{i}^{o}\right)^{2}$ is the production cost of $i$. The oligopoly production of farmer $i$ is given as

$$
q_{i}^{o}=\frac{\alpha}{\left(\beta+2 A_{i}\right)\left(1+\beta \sum_{j=1}^{N} \frac{1}{\beta+2 A_{j}}\right)} .
$$

\subsection{Marketing cooperative with direct selling: the hybrid case}

Here, we still consider a marketing cooperative of $N$ farmers. Each farmer $i$ decides and produces the good in quantity of $Q_{i}$ at a total cost of $C_{i}\left(Q_{i}\right)=A_{i} Q_{i}^{2}$. In addition to their cooperative, the farmers can sell by themselves a fraction of their production directly on a local market (as in Jang \& Klein (2011) among others). Each farmer $i$ has to choose the proportion $\theta_{i}$ (of his production $Q_{i}$ ) to sell to the cooperative ${ }^{13}$ The rest $1-\theta_{i}$ is sold on the local market. We assume that the local market is common for the $N$ farmers, and is an oligopolistic market with Cournot competition. The demand function on the local market is

$$
P^{D}=\alpha-\beta\left(\sum_{j=1}^{N}\left(1-\theta_{j}\right) Q_{j}\right)
$$

where $P^{D}$ is the price on the local market and $\alpha, \beta>0$ are parameters. The cooperative buys the product from the farmers at the unit price $P_{c}$ and sells it on a large competitive market (non local market) at a unit price $P$. We assume that the competitive market where the cooperative sells and the local market are separated 14 The profit of the cooperative is then

$$
\Pi_{c}=\left(P-P_{c}\right) \sum_{j=1}^{N} \theta_{j} Q_{j}
$$

\footnotetext{
$\sqrt[13]{\text { Albaek \& Schultz }}(1997)$ argued that, in many cooperatives (particularly Danish cooperatives), the farmers decide individually on the amount of production to deliver to the cooperative. Also, Giannakas \& Fulton (2005) pointed out the prevalence of open-membership cooperatives, and, according to (Petraglia \& Rogers, 1999), open-membership implies the cooperative will serve as quantity-taker with respect to members' output.

${ }^{14}$ Implicitly, we consider that farmers will not decide to sell directly (i.e not through cooperative) on the non local market. This paradigm is realistic because of transaction costs. For farmers, selling on the non local market would create higher transaction costs than selling on the local market. Since one of the attributes of cooperatives is transaction costs reducing (Holloway et al., 2000, Roy \& Thorat, 2008, Markelova et al., 2009, Fischer \& Qaim 2012), and farmers cannot influence the price $P$, it is reasonable to consider that they will prefer using the cooperative than selling directly on the non local market. We discuss in Section 6 the case where both the cooperative and the farmers operate on the local market.
} 
As owner of the cooperative, each farmer earns a proportion $b_{c}$ of the profit made by the cooperative 15 The total profit of the farmer $i$ is 16

$$
V_{i}=P_{c} \theta_{i} Q_{i}-A_{i} Q_{i}^{2}+b_{c} \Pi_{c}+P^{D}\left(1-\theta_{i}\right) Q_{i}
$$

In the game, the cooperative chooses $P_{c}$ that maximizes $\Pi_{c}$. Basing on $P_{c}$, farmer $j(j=$ $1, \cdots, N)$ chooses $Q_{j}$ and $\theta_{j}$ that maximize $V_{j}$.

\subsection{Remark}

Even though we consider the cooperative maximizes its profits, our results cannot be generalized to investor-owned-firms (IOFs). In other words, we cannot insure that our model remains valid beyond cooperation and direct selling environment. Indeed, IOFs will behave like a monopsonist and will decide on and control over the quantity to purchase from the farmers. Since farmers are price-takers, the IOF will pay them according to their supply, i.e, aggregated marginal cost (Karantininis \& Zago, 2001). In contrast, the cooperative pays according to the conditions on the competitive market on which it sells the products delivered. If these conditions get better, the cooperative will pay more. This is not necessary true for the IOF who may still pay the same price, even if the price increases in the large competitive market. In this paper, unlike IOFs, the cooperative is considered as an association for which farmers are owners and controllers, so that farmers' production decision coincides with (or is close to) the cooperative's decision. An illustration of how our results are affected is provided in Proposition G.1 (Appendix G) where an introduction of capacity constraint changes some of our results.

\section{Optimal behaviors}

In this section, we provide the optimal decision made by different agents acting in our framework of cooperative with direct selling. Proposition 3.1 and 3.2 give price and quantities in equilibrium.

\footnotetext{
${ }^{15}$ We could consider that the profit of the cooperative is shared accordingly to the quantity delivered by the farmer, and farmer $i$ receives a share $\theta_{i} Q_{i} / \Sigma \theta_{j} Q_{j}$ of the profit. In that case, farmer $i$ 's profit is $P_{c} \theta_{i} Q_{i}-$ $A_{i} Q_{i}^{2}+b\left(P-P_{c}\right) \theta_{i} Q_{i}+P^{D}\left(1-\theta_{i}\right) Q_{i}$, where $0<b<1$ is the part of the profit the cooperative decides to share out. As we said before, proportionally profit distribution does not change our results. Indeed, even if the profit is proportionally shared, an increase of the quantity delivered by a given farmer is also profitable for the other farmers. So, proportionally profit sharing does not completely solve the free rider problem, and might not incite farmers to deliver more. This drawback of the proportionally profit sharing is highlighted by Ortmann \& King (2007), regarding new members and existing members of the cooperative. On the other hand, the organizational structure of many cooperatives is changing, and the benefits sharing rules are becoming more hybrid and complex (Deller et al., 2009 , Bijman et al. 2013).

${ }^{16}$ Our way to formalize the farmer's objective matches well with Bontems \& Fulton (2009), among others papers. In Bontems \& Fulton (2009), page 323, we can read: "The farmers who own the cooperative, are interested in maximizing the returns from each of their own operations plus their share of the profits generated by the cooperative".
} 
Proposition 3.1. The optimal unit price at which the cooperative buys the product from the farmers is

$$
P_{c}^{*}=\frac{N \alpha}{2\left(1-b_{c}\right)\left(N+\beta(N+1) \sum_{j=1}^{N} \frac{1}{2 A_{j}}\right)}+\frac{\left(1-2 b_{c}\right) P}{2\left(1-b_{c}\right)}
$$

Proof. See Appendix A for the proof of Propositions 3.1 and 3.2 .

Proposition 3.2. The quantity produced by the farmer $i$ is

$$
Q_{i}^{*}=\frac{N \alpha}{4 A_{i}\left(N+\beta(N+1) \sum_{j=1}^{N} \frac{1}{2 A_{j}}\right)}+\frac{P}{4 A_{i}}
$$

The delivery price chosen by the cooperative is always higher in the framework of marketing cooperative with direct selling (eq. 11) than in full marketing cooperative (eq. 5). To incite farmers to deliver their products, the cooperative has to challenge the local market, and this challenge becomes more serious as the conditions on the local market ( $\alpha$ and $\beta$ ) allow farmers to get higher local price $P^{D}$. On the other hand, unlike the full marketing cooperative, the price proposed by the cooperative does not necessarily decrease with $b_{c}$, the part of the cooperative's profit earned by each farmer. Here, the result depends on the characteristics of the local market and the large competitive market as well, i.e the challenge the cooperative has to face due to the existence of the local market. If the challenge is not "serious" enough $\left(\frac{\alpha}{P} \leq \frac{N+\beta(N+1) \sum \frac{1}{2 A_{j}}}{N}\right)$, then the cooperative has much leeway to adjust downward (decrease) its price $P_{c}$ to an increase of $b_{c}$. On the contrary, if the challenge is too serious $\left(\frac{\alpha}{P}>\frac{N+\beta(N+1) \sum \frac{1}{2 A_{j}}}{N}\right)$, to incite farmers to sell to them, the cooperative has to choose a price $P_{c}$ greater than $P$. In such a situation, the profit is a loss, and an increase of $b_{c}$ implies an increase of the loss borne by members. As a consequence, to compensate for the loss, the cooperative has to upwardly adjust the price $P_{c}$. However, the capacity of the cooperative to price above $P$ is limited. If the loss is too high, as seen in Proposition 3.3 , no farmer will sell to the cooperative.

Compared to the outcome of full marketing cooperating, the quantity of goods produced by each farmer increases with the introduction of a local market. This increase in production is driven by two facts. First, in order to compete with the local market and incite the farmer to soll to them his whole production, the cooperative has to increase the price $P_{c}$. Second, the increase of the production is also due to the oligopolistic structure of the local market. If the farmers were organized in price-taker cooperative on the local market, the result would not be the same. The market whose cooperative has better conditions would attract all the production.

If the introduction of direct selling increases farms's output, it is worth knowing the proportion of this output farmers deliver to the cooperative.

Proposition 3.3. Let $\theta_{i}$ be the part of his production that farmer $i$ allocates to the cooperative. Then

.If $\quad \frac{\alpha}{P} \leq \underline{\alpha}$ then $1-\theta_{i}=0$ 
.If $\underline{\alpha}<\frac{\alpha}{P}<\bar{\alpha}_{i}$ then $1-\theta_{i}=\frac{2 A_{i}}{\beta(N+1)}\left[\frac{\alpha\left(N+2 \beta(N+1) \sum \frac{1}{2 A_{j}}\right)-P\left(N+\beta(N+1) \sum \frac{1}{2 A_{j}}\right)}{N \alpha+P\left(N+\beta(N+1) \sum \frac{1}{2 A_{j}}\right)}\right]$

. If $\frac{\alpha}{P} \geq \bar{\alpha}_{i}$ then $1-\theta_{i}=1$

where $\quad \underline{\alpha}=\frac{N+\beta(N+1) \sum \frac{1}{2 A_{j}}}{N+2 \beta(N+1) \sum \frac{1}{2 A_{j}}} \quad$ and $\quad \bar{\alpha}_{i}=\frac{\left(2 A_{i}+\beta(N+1)\right)\left(N+\beta(N+1) \sum \frac{1}{2 A_{j}}\right)}{2 A_{i}\left(N+2 \beta(N+1) \sum \frac{1}{2 A_{j}}\right)-\beta N(N+1)}$

Proof. See Appendix B.

Proposition 3.3, illustrated in Figure 1, gives how members of the cooperative share their production between the two markets (cooperative and local market). They compare the maximum price they can get on the local market $(\alpha)$ with the price at which the cooperative sells on the large competitive market. Farmers are more likely to sell to the cooperative if the other alternative (local market) is less profitable. This result is in line with the work of Pascucci et al. (2012) concerning Italian farmers. Also, more efficient farmers (lower $A$ ) or larger farms are more likely to sell to the cooperative. This theoretical result is confirmed by various empirical works Gale, 1997, Low \& Vogel, 2011; Timmons \& Wang, 2010, Uematsu $\&$ Mishra, 2011). This finding also seems to conform empirical evidences found in Ethiopia by Bernard et al. (2008) ${ }^{17}$ Moreover, using a theoretical model which is different from ours, Jang \& Klein (2011) came to similar result. Low \& Vogel (2011) explain this propensity of smaller farms for direct selling by the fact that small farms do not have enough volume to meet the demand of large distributors, unlike large farms which have this capacity. However, as we study in Section 4, more efficient farmers prefer to sell more to cooperative, in order to limit competition on local market and get higher direct selling price, since they have market power on the local market.

As we can see from Figure 1, depending on the profitability of each part (cooperative and local market), a given farmer could sell his whole production to the cooperative and sell nothing on the local market, or could sell his whole production on the local market and nothing to the cooperative. Klein et al. (1997) observe this in Canadian data concerning the volume of business members have with their cooperative. Specifically, in Proposition $3.3 \underline{\alpha}$ is the same for all farmers. It means that the decision to sell or not on the local market is the same for all the farmers. Indeed, deciding to sell on the local market depends, in general on the nature of the product and not on the efficiency of the farmers. For instance, fruits and vegetable are more prone to direct selling than non processed milk, rape, cocoa. If the product is valuable and in demand on local market, each farmer perfers to distribute the goods via direct sales. However, if the farmer decides to sell locally, the proportion of production to sell depends on the volume of that production. The reason is that demand is not atomistic on the local market.

\footnotetext{
${ }^{17}$ Bernard et al. (2008) compared the commercialization behavior of smallholders cooperatives members with non cooperatives members. They found that, even though cooperatives secure higher prices for their members, smaller farmers (members) tend to reduce the output marketed through the cooperative, as a response to the higher prices. However the opposite is true for larger farms. Of course, in our model, smaller farms (higher $A$ ) do not reduce delivering with prices increase, but their increase in selling is lower than that of larger farms (lower $A$ ).
} 


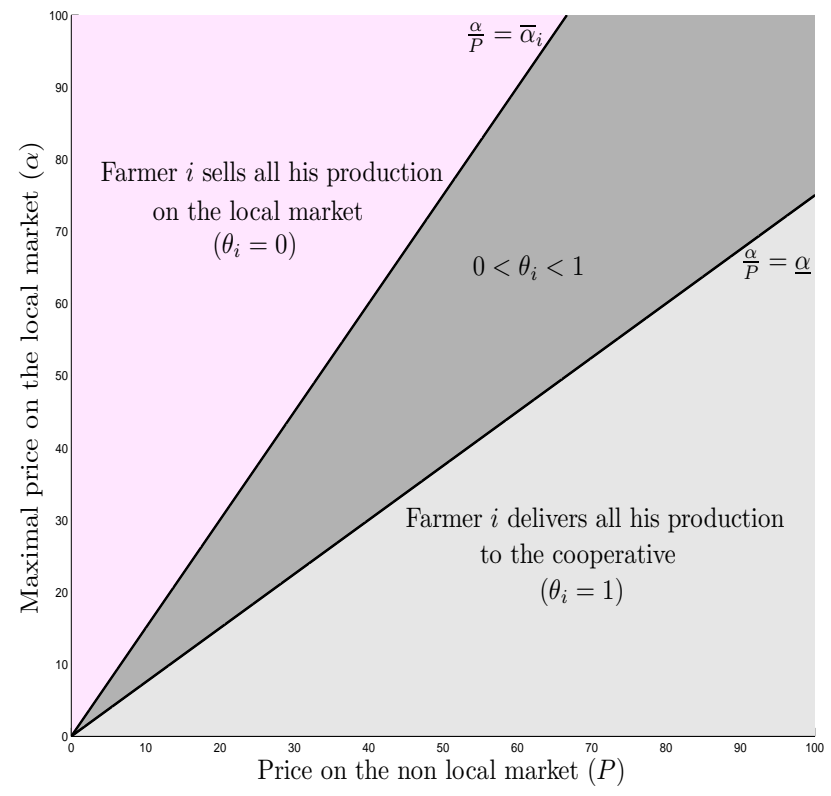

Figure 1: Markets characteristics and selling rate of the cooperative members.

\section{The effect of the cooperative on local market transactions}

After deriving the optimal decision by agents, we now start analyzing the interdependence between the two parts (cooperative and local market) of the environment under study. Specifically, in this section, we study how quantities sold and profits made by farmers on local markets are affected by the fact that they are members of a cooperative through which they can sell part of their production.

\subsection{On sales volume}

The following proposition gives a first result about quantities sold on the local market.

Proposition 4.1. If the cooperative has no capacity constraint, and $\frac{\alpha}{P}<\bar{\alpha}_{i}$ for all $i$, then all the farmers sell the same quantity of products on the local market, i.e, $\left(1-\theta_{1}\right) Q_{1}=$ $\left(1-\theta_{2}\right) Q_{2}=\cdots=\left(1-\theta_{N}\right) Q_{N}$.

Proof. See Appendix C.

Proposition 4.1 states that, if the market conditions are such that all farmers sell to the cooperative, they will sell the same quantity on the local market, even if they do not have the same cost function and do not produce the same quantity. In other words, if the local demand is not sufficient enough to allow farmers to sell all their production on the local market and get an interesting price, they collude on quantities. Farmers behave as if they use the cooperative to limit competition on the local market. This is true for the higher volume producers (lower $A$ ). The smaller farms who can sell all their production on the local market 
do not participate in this "collusion". Indeed, as mentioned by Uematsu \& Mishra (2011), direct selling allows producers to receive a better price, because they have market power. Therefore, farmers who produce in large quantities, sell more to the cooperative in order to secure this higher price on local market ${ }^{18}$ The implication is that (as one could deduce from Proposition 3.3), farmers become more and more inclined to deliver to the cooperative, as the number of farmers increases. And when the number of farmers increases, the cooperative can afford to reduce the delivering price $P_{c}$, as one could see from Proposition 3.1 by considering homogeneous production cost function. In other words, the cooperative plays an important role in the direct selling decision. Proposition 4.2, illustrated in Figure 2 confirms this role when the farmers have the same production cost function.

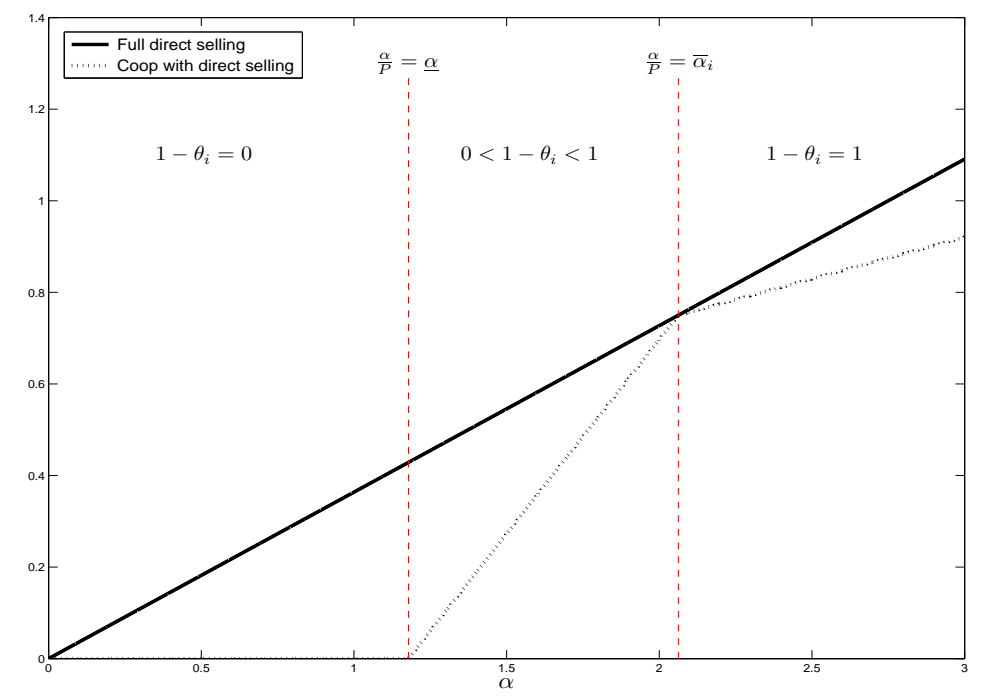

Figure 2: Production total quantity sold on local market.We set $N=2, A_{i}=2 \forall i, P=1.5$, $\beta=0.5$, and $b_{c}=\frac{1}{N+1}$.

Proposition 4.2. Assume that the farmers have the same production cost, i.e. $A_{j}=A, \forall j$. The total quantity sold on the local market is always lower in a marketing cooperative with direct selling than in full direct selling, i.e. $\sum_{j=1}^{N}\left(1-\theta_{j}\right) Q_{j}^{*} \leq \sum_{j=1}^{N} q_{j}^{o}$.

Proof. See Appendix F.

According to Proposition 4.2, compared to the full direct selling, when farmers are organized in cooperative, they sell less on local market. This remains true even if farmers sell nothing to the cooperative. Therefore, the possibility of selling through a cooperative enables farmers to "protect" the local market price, which makes them better off. However, this situation could mean that consumers who purchase on the local market are worse off. This reduction of output, due to the presence of the cooperative, is strongly stated in Proposition 4.3 .

\footnotetext{
${ }^{18}$ However, as we show in Appendix $\mathrm{G}$ if the cooperative is subject to a capacity constraint, and restricts the amount to sell, Proposition 4.1 is not valid. Therefore, farmers do not have sufficient leeway to regulate by themselves the amount of product to sell on the local market.
} 
Proposition 4.3. Assume that the farmers have the same production cost, i.e. $A_{j}=A, \forall j$. The total production of the farmers is higher in cooperation with direct selling than in full direct selling (i.e. $\sum_{j=1}^{N} Q_{j}^{*}>\sum_{j=1}^{N} q_{j}^{o}$ ) if $\frac{\alpha}{P}<\frac{2 A+\beta(N+1)}{2 A}$. Otherwise, the farmers produce less in cooperation with direct selling than in full direct selling.

Proof. See Appendix E.

According to Proposition 4.3, farmers might produce less in a marketing cooperative with direct selling than in full direct selling, if local demand is such that they can get a better price on the local market. In other words, it is possible that farmers produce less when they have access to two markets (cooperative and local market) than when they have access to just one market (local market). From this result and the fact that farmers always produce more in a marketing cooperative with direct selling than in a full marketing cooperative, we suspect that the presence of the cooperative might be a source of output reduction. Indeed, it is well known in the literature that a cooperative always produces more output than the investor-owned firm (Nourse, 1922; Tennbakk, 1995; Bontems \& Fulton, 2009, Giannakas \& Fulton, 2005). Many authors made the case for the pro-competition effect of the cooperative (Petraglia \& Rogers, 1999: Deller et al. 2009 ${ }^{19}$. Specifically, there is a pro-competitive effect in the case where the cooperative does not have control over farmers' production decisions. If the cooperative can restrict the farms' product then it might reduce output (Youde, 1978; Sexton \& Iskow, 1988, Sexton, 1990). However, in our model, the cooperative does not have control over farmers' production, and yet, it might reduce farms' output. In fact, what we know from the literature is that a cooperative induces a competition effect when challenging an IOF. But little research has been carried out concerning the situation of marketing cooperatives challenging their own members who operate on an oligopolistic local market. Indeed, marketing cooperatives can reduce output for two reasons. First, according to Propositions 3.3 and 4.3 a cooperative reduces farms' output, in the case where no farmers sell to the cooperative. Without the cooperative, farmers would be in a standard oligopolistic market. With the cooperative, since farmers know that they have another option (selling to cooperative), they can increase price on the local market by reducing output. As we will see, this decision to reduce output, increases farmers profits. The second reason is that our framework is a combination of cooperation and oligopolistic competition. Within a certain context, it is well known that the cooperative game structure yields less output than oligopolistic structure. Therefore, the combination of both structures may reduce output, if the performance of the cooperative is not sufficient enough to incite farmers to sell.

\subsection{On farmers' profits}

In the preceding section, we have seen that with a marketing cooperative, farmers reduce their sales on the local market. We now study how this result affects the individual profit made by farmers on the local market. Specifically, we compare the profit made from selling through full direct selling with the profit made on local markets through a marketing cooperative with

\footnotetext{
${ }^{19}$ Sexton (1990) used the term "yardstick of competition".
} 
direct selling. In general, the result is ambiguous. We therefore use graphical analysis to find that the local market profit might be higher, depending on the parameters of the model. In Figure 3, we plot the profits of the farmers in full direct selling and in a marketing cooperative with direct selling, as functions of the number of farmers. For few farmers, the profit made on

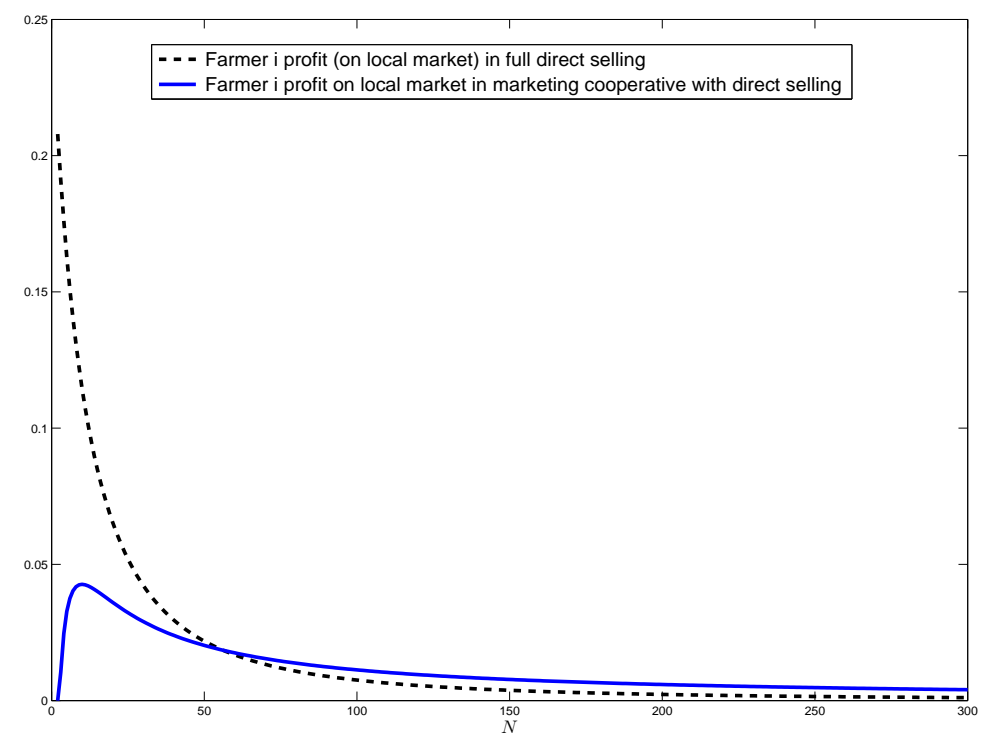

Figure 3: Farmers' individual profits on local market. We set $A_{i}=2 \forall i, P=1.15, \alpha=1, \beta=0.1$, and $b_{c}=\frac{1}{N+1}$.

local markets is higher in full direct selling than in marketing cooperative with direct selling. But as the number of farmers $(N)$ goes up, competition also increases on the local market. Unlike the framework of a marketing cooperative with direct selling, in full direct selling farmers do not have the opportunity to turn to other markets and to limit competition on the local market. As a consequence, the profit decreases faster in full direct selling than in marketing cooperative with direct selling. Above a certain value of $N$, the profit in marketing cooperative with direct selling becomes higher.

It is well known that, in standard oligopolistic market, the firms' individual profit decreases with the number of firms, as we see in Figure 3 for the farmers' individual profit in full direct selling. However, the result is not necessarily the same when the oligopolistic firms are also organized in a marketing cooperative through which they can sell their production on other markets. Indeed in our framework, for some characteristics of the markets, individual profit may increase with the number of farmers. As shown in Figure 3 , for lower values of $N$, an increase of $N$ leads the farmers to sell more to the cooperative in order to avoid a price decrease on the local market. Under certain conditions, the positive effect (of selling to the cooperative) on the local market profit may overcompensate for the negative effect of an increase of the number of farmers. As a consequence, the individual profit could increase. But for many farmers, the competition on local market becomes too hard to be compensated for. In Appendix $\mathrm{H}$, we draw the profits as functions of $\alpha, \beta, P$, and $A$. 
Proposition 4.4. Let $V_{i}^{D}$ be the profit of the farmer $i$ made on the local market, in a structure of marketing cooperative with direct selling. We denote by $K$ the quantity of goods that the farmer decides to sell on local market. Then,

$$
\text { If } \quad K>\frac{\alpha}{2(N-1) \beta} \text { then } \frac{\partial V_{i}^{D}}{\partial K}<0
$$

Proof. See Appendix D.

Proposition 4.4 gives a more formal result about the effect selling has on the individual farmer's profit made on the local market. If, depending on his efficiency, a farmer produces a greater volume of goods than a specific threshold, then it is better for him to sell part of this production to the cooperative. In other words, even if direct selling opportunity exists, large farm holders may still have a vested interest in being members of a marketing cooperative.

In this section, we have seen that the volume of business farmers conduct with their marketing cooperative, affects their performance in direct selling. Even if the cooperative does not have market power, it enables farmers to strengthen their market power on the local market. However, this role of the marketing cooperative is undermined if, for some reasons, the cooperative can restrict the amount of product farmers are allowed to sell. Such a situation could occur if the cooperative has a capacity constraint or the decisions of the farmers does not correspond to those made by the managers of the cooperative.

\section{Direct selling and delivery to the cooperative}

In this section, we examine the effect of the introduction of direct selling on the quantities delivered by farmers to their cooperative. Indeed, there are some concerns about whether the cooperative should allow or not its members to sell their production by themselves directly to the consumer. The legitimacy of these concerns lies in the fact that the marketing cooperative that allows its members to sell directly on a local market is likely to experience supply shortage. However, we show that allowing direct selling might be beneficial for the cooperative.

Proposition 5.1. Let $\theta_{j}$ be the fraction of his production $Q_{j}^{*}$ that a farmer $j(j=1, \cdots, N)$ allocates to the cooperative, in a model of cooperative with direct selling. We denote by $\hat{q}_{j}$ the production of farmer $j$ in a model of cooperative without direct selling. Then,

$$
\text { If } \alpha<P \quad \text { then } \quad \sum_{j=1}^{N} \theta_{j} Q_{j}^{*}>\sum_{j=1}^{N} \hat{q}_{j}
$$

Proof. The proof consists simply in calculating the expression of each side of the inequality and making the comparison.

Proposition 5.1 (illustrated by Figure 4 states that, if the maximum price farmers get on the local market is lower than the price the cooperative gets on the large competitive market, then the farmers will sell more to the cooperative in marketing cooperative with direct selling than in full marketing cooperative. Introducing direct selling brings two modifications to the initial full marketing cooperative. First, in addition to the cooperative, farmers have access to other market. In other words, they have more opportunity to sell their product. Second, 


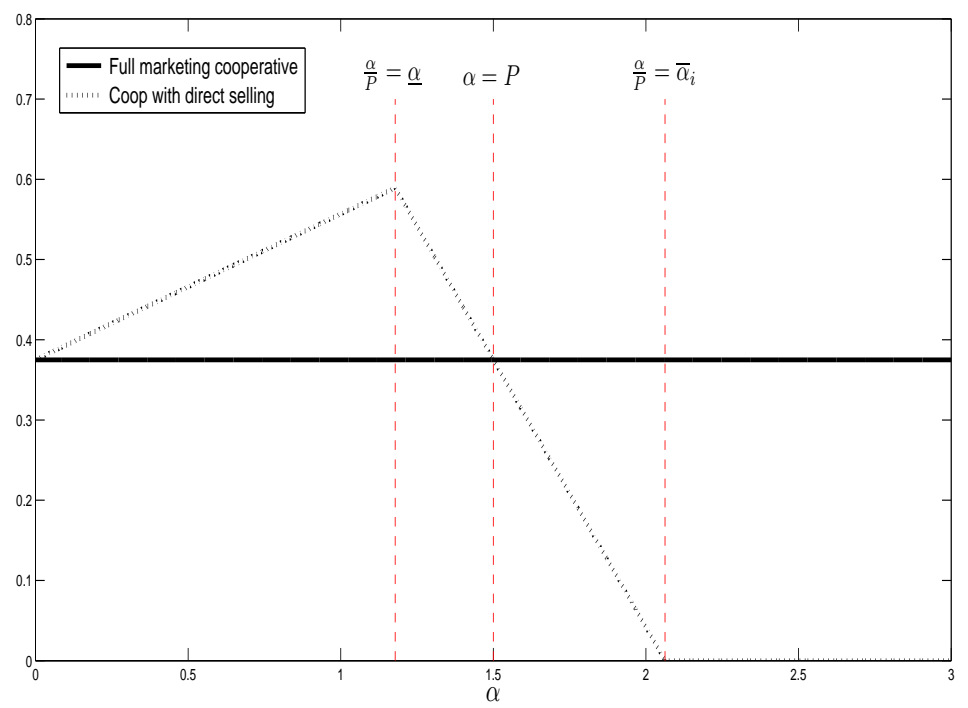

Figure 4: Production total quantity delivered to the cooperative. We set $N=2, A_{i}=2 \forall i$, $P=1.5, \beta=0.5$, and $b_{c}=\frac{1}{N+1}$.

direct selling adds an oligopoly structure to the initial cooperation. With oligopoly structure, farmers compete with each other more than in cooperation. These two modifications incite farmers to produce more. But if they produce more and the local demand is not sufficient to generate a reasonnable price, the cooperative will be sold more produce. Direct selling may create a healthy emulation that could be beneficial for the cooperative. In contrast, if demand on the local market is promising then the cooperative will be worse off. Therefore, the decision of whether a cooperative should allow direct selling depends on the characteristics of the local market, regarding the competitive price of the large market.

As shown in Figure $5(5 a, 5 b$, and $5 d)$, if $\alpha$ is lower than $P$, the consequence of direct selling might be an increase of the profit made by the farmers from their business with the cooperative. It is the straightforward implication of the fact that farmers provide more and the cooperative proposes a higher price. In other words, the healthy emulation leading to more production, might have a positive effect on the performance of farmers' activities with the cooperative.

In total, if for some given values of parameters, direct selling has a positive effect on individual profit made with cooperative, and the cooperative has a positive effect on individual profit made on the local market, then a marketing cooperative with direct selling can have positive effect on total profit (sum of profit made on the local market and profit made with the cooperative). We give an illustration in Figure 6 where we draw the total individual profits of farmers in the three market structures considered in this paper.

In the preceding sections $(4$ and 5), we have studied the interdependence between the cooperative market and the direct selling market. Specifically, we have seen how quantities produced and sold are affected by each part. We now summarize these results in Figure 7 

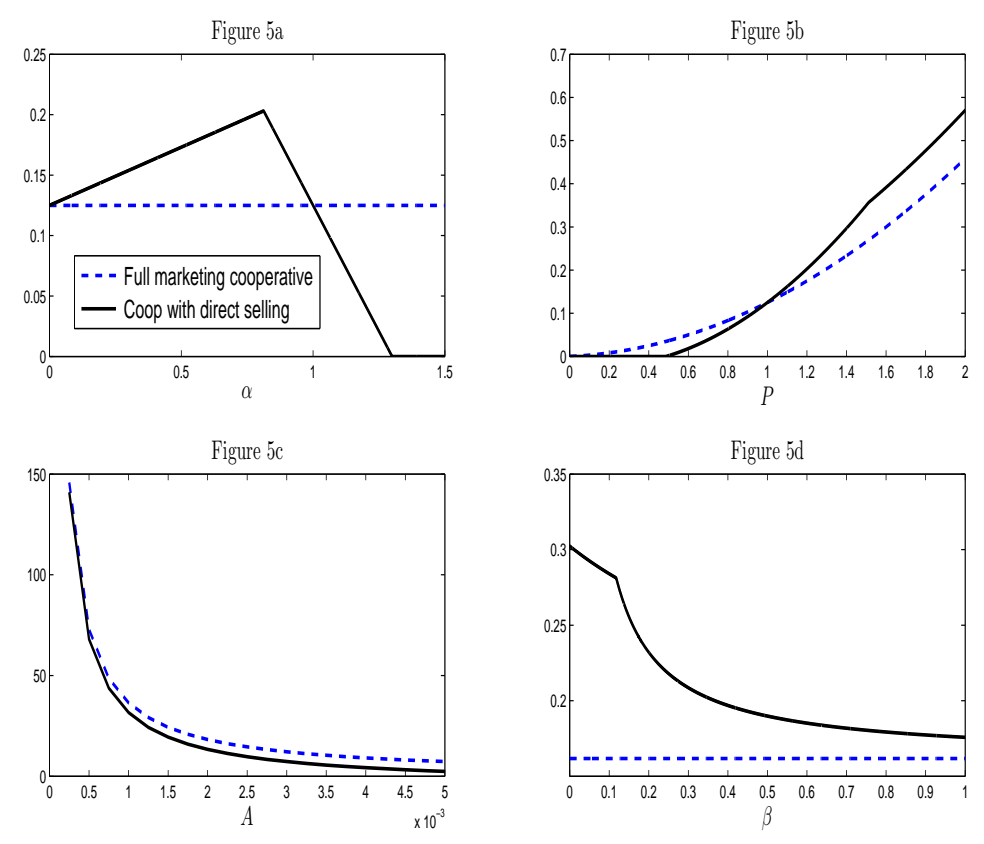

Figure 5: Farmers' individual profits from their activities with the cooperative. For Figure 5a, we set $N=2, A_{i}=1 \forall i, P=1, \beta=0.2$, and $b_{c}=\frac{1}{N+1}$. For Figure $5 \mathrm{~b}, N=2, A_{i}=1 \forall i, \alpha=1$, $\beta=0.7$, and $b_{c}=\frac{1}{N+1}$. For Figure $5 \mathrm{c}, N=2, P=0.5, \alpha=1.5, \beta=0.01$, and $b_{c}=\frac{1}{N+1}$. For Figure $5 \mathrm{~d}, N=2, A_{i}=1 \forall i, \alpha=1, P=1.15$, and $b_{c}=\frac{1}{N+1}$

which gives quantities produced and sold on the two parts, under different market structures.

\section{Discussion: The case where cooperative and members operate on the same local market}

Up to now, we have considered that the direct selling market and the market where the cooperative sells are separate, in that farmers do not sell directly on the large competitive market, and the cooperative does not operate on the local market. Due to transaction costs, it is reasonable to assume that farmers will not decide to sell on the large competitive market. In contrast, the marketing cooperative can decide to sell on the local market at the same time. In this section, we study what happens if farmers and the cooperative decide to be present on the local market. We show that, in such a situation, direct and cooperative selling can no longer coexist.

Indeed, the farmer $i$ 's total profit is $V_{i}^{L}=P_{c} \theta_{i} Q_{i}-A_{i} Q_{i}^{2}+b_{c} \Pi_{c}+P^{D}\left(1-\theta_{i}\right) Q_{i}$ where $\Pi_{c}=\left(P^{D}-P_{c}\right) \sum_{j=1}^{N} \theta_{j} Q_{j}$ and $P^{D}=\alpha-\beta\left(\sum_{j=1}^{N} Q_{j}\right)$. The first derivative of $V_{i}^{L}$ with respect to $\theta_{i}$ is equal to $\left(1-b_{c}\right)\left(P_{c}-\alpha+\beta\left(\sum_{j=1}^{N} Q_{j}\right)\right) Q_{i}$. There are three cases: $P_{c}<P^{D}$, $P_{c}>P^{D}$, and $P_{c}=P^{D}$. If $P_{c}<P^{D}$ then farmers will not sell to the cooperative, i.e. $\theta_{j}=0$ for all $j$, and there is no cooperative selling and only direct selling. The cooperative would disappear. If $P_{c}>P^{D}$ then farmers will sell all their production to the cooperative, i.e. $\theta_{j}=1$ for all $j$ and there is no direct selling. Such a situation could occur if the cooperative receives 

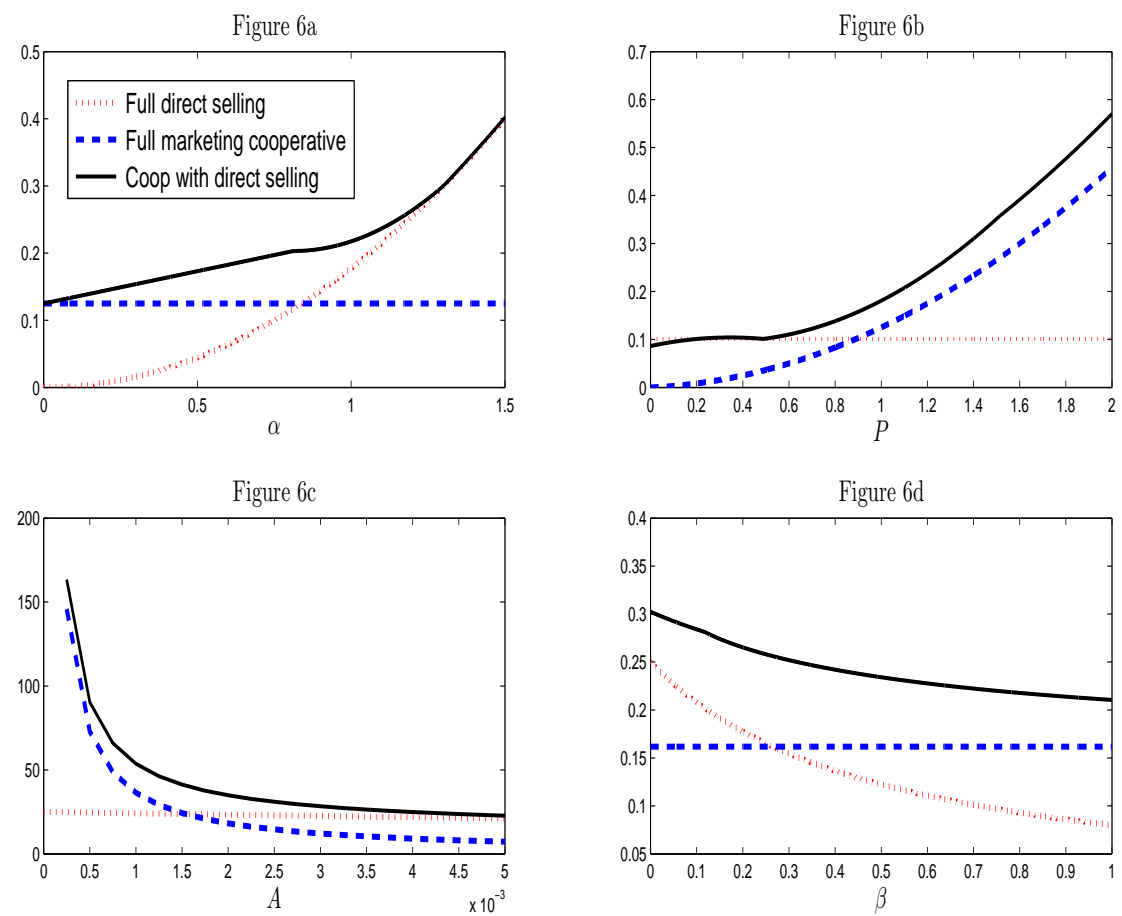

Figure 6: Farmers' individual total profits for different market structures. For Figure 6a, we set $N=2, A_{i}=1 \forall i, P=1, \beta=0.2$, and $b_{c}=\frac{1}{N+1}$. For Figure $6 \mathrm{~b}, N=2, A_{i}=1 \forall i, \alpha=1, \beta=0.7$, and $b_{c}=\frac{1}{N+1}$. For Figure 6c, $N=2, P=0.5, \alpha=1.5, \beta=0.01$, and $b_{c}=\frac{1}{N+1}$. For Figure $6 \mathrm{~d}$, $N=2, A_{i}=1 \forall i, \alpha=1, P=1.15$, and $b_{c}=\frac{1}{N+1}$

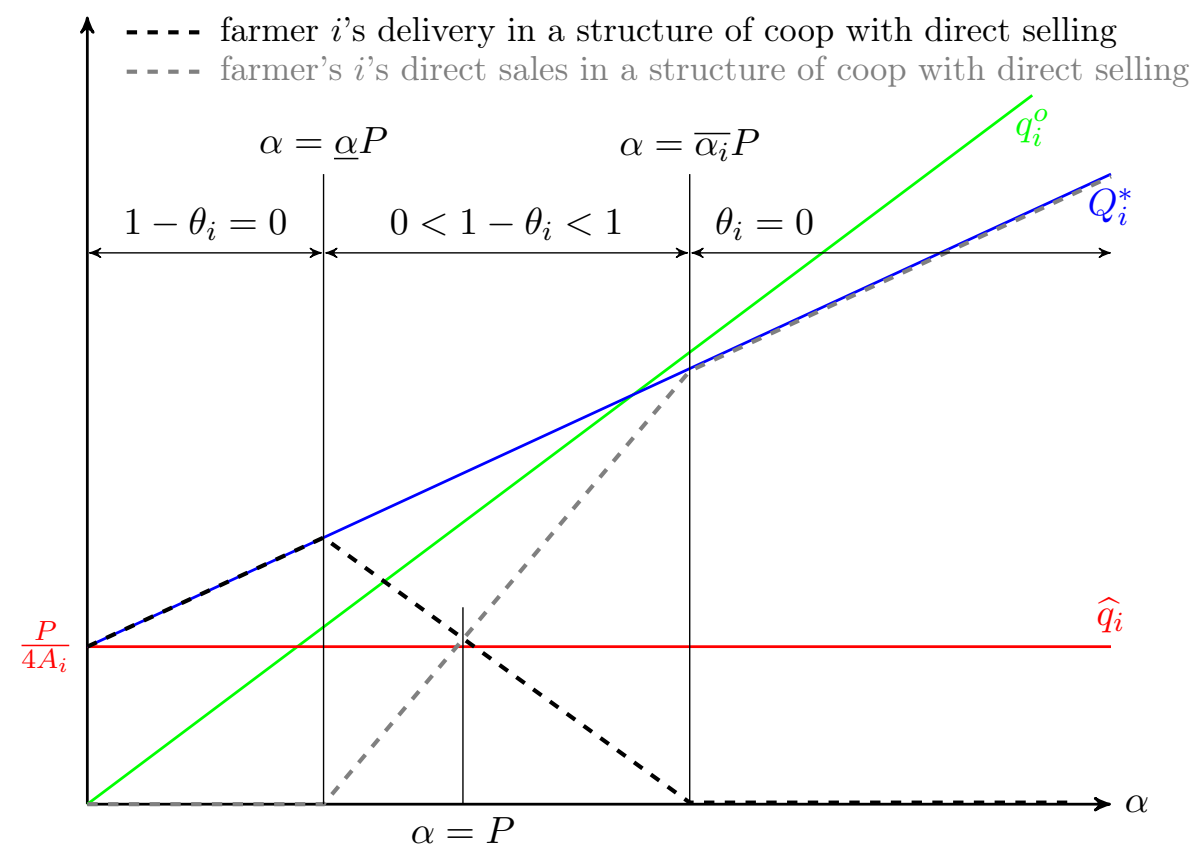

Figure 7: Quantities produced and delivery schedule 
subsidies from the government or other institutions outside the market. Suppose now that $P_{c}=P^{D}$, i.e. $P_{c}-\alpha+\beta\left(\sum_{j=1}^{N} Q_{j}\right)=0$. The first-order condition with respect to $Q_{i}$ yields the optimal quantity $Q_{i}^{L}$ produced by the farmer $i$ as

$$
Q_{i}^{L}=\frac{\alpha}{\left(2 A_{i}+\beta\left(1-\theta_{i}\right)\right)\left(1+\beta \sum_{j=1}^{N} \frac{1+b_{c} \theta_{j}}{2 A_{j}+\beta\left(1-\theta_{j}\right)}\right)}
$$

Since $P_{c}=P^{D}$, the profit of the cooperative is equal to zero and the total profit of any member $i$ becomes $V_{i}^{L}=\left(\alpha-\beta\left(\sum_{j=1}^{N} Q_{j}\right)\right) Q_{i}-A_{i} Q_{i}^{2}$, which is maximized by the oligopoly production 20 As a consequence, we have $\theta_{i}=0$, i.e. there is nothing sold to the cooperative and only direct selling.

In other words, direct selling is not suitable for the cooperatives who sell on the same market as farmers. It is more appropriate for large cooperatives who can have access to large foreign markets.

\section{Concluding Remarks}

In this paper, we study the market structure of a marketing cooperative with direct selling, in which many farmers organized in cooperatives, can sell both to the cooperative and directly to consumers on a local market. Using a theoretical model, we show that direct selling and marketing through a cooperation might be beneficial for each party. Even though the cooperative does not have market power, it could have an anti-competitive effect on the direct selling market, and thus benefit farmers. Conversely, direct selling can create a healthy emulation and incite farmers to increase production that could benefit the cooperative.

The contribution of this paper is twofold. First, it is an attempt to build a theoretical framework of a marketing cooperative coupled with direct selling. To our knowledge, this is among the first theoretical works about direct selling and cooperatives. Jang \& Klein (2011) also considered a framework in which farmers simultaneously sell to marketing cooperatives and on local markets. But in Jang \& Klein (2011), prices and demand are given. Farmers only decide on how to share production between the two parts. Second, this paper contributes to clear up the cooperatives' concerns about whether to allow members to directly sell to consumers.

There are several ways to extend our paper. We have considered that farmers produce a homogeneous unique good. We have also abstracted from the possibility for farmers to sell to IOFs. However, in many cases, they produce more than one good, and decide on which one to sell to the cooperative, through direct selling, or to IOFs. Moreover, cooperatives can demand a minimum volume (fixed volume or percentage of production) from its members. A minimum supply might mitigate the anti-competitive effect we mention in this paper. Finally, it might be interesting to go over the standard oligopolistic setup we consider for the local market, as it is well known that direct selling could involve spatial competition.

\footnotetext{
${ }^{20}$ The oligopoly production is the quantity produced by the farmers when there is no cooperative and the farmers are in oligopolistic competition on the local market. We found in Section 2.2 the expression of the oligopoly production.
} 


\section{References}

Albaek, S., \& Schultz, C. 1997. One Cow, One Vote? Scandinavian Journal of Economics, 99(4), 597-615.

Albaek, S., \& Schultz, C. 1998. On the Relative Advantage of Cooperatives. Economics Letters, 59(3), 397-401.

Bernard, T., Taffesse, A. S., \& Gabre-Madhin, E. 2008. Impact of Cooperatives on Smallholders' Commercialization Behavior Evidence from Ethiopia. Agricultural Economics, 39(2), $147-161$.

Bijman, J., \& Verhees, F. 2011. Members or Customers? Farmers Commitment to Supply Cooperatives. Paper presented at the International Conference on the Economics and Management of Networks, 1-3 December 2011, Limassol, Cyprus.

Bijman, J., Hendrikse, G., \& van Oijen, A. 2013. Accommodating Two Worlds in One Organisation: Changing Board Models in Agricultural Cooperatives. Managerial and Decision Economics, 34(3-5), 204-217.

Bond, J. K. 2006. Cooperative Growth and Decline: A Game Theoretic Approach to Understanding Members Allocation Choices. Selected Paper prepared for presentation at the American Agricultural Economics Association Annual Meeting, Long Beach, California, July 23-26, 2006, available at http://ageconsearch.umn.edu/bitstream/21279/1/sp06ke04.pdf .

Bontems, P., \& Fulton, M. 2009. Organizational Structure, Redistribution and the Endogeneity of Cost: Cooperatives, Investor-owned Firms and the Cost of Procurement. Journal of Economic Behavior and Organization, 72(1), 322-343.

Boyle, G. E. 2004. The Economic Efficiency of Irish Dairy Marketing Cooperatives. Agribusiness, 20(2), 143-153.

Brown, C., \& Miller, S. 2008. The Impacts of Local Markets: A Review of Research on Farmers Markets and Community Supported Agriculture. American Journal of Agricultural Economics, 90(5), 1296-1302.

Cakir, M., \& Balagtas, J. V. 2012. Estimating Market Power of U.S. Dairy Cooperatives in the Fluid Milk. American Journal of Agricultural Economics, 94(3), 647-658.

Camanzi, L., Malorgio, G., \& Garcia Azcarate, T. 2011. The role of Producer Organizations in Supply Concentration and Marketing: A comparison between European Countries in the Fruit and Vegetable Sector. Journal of Food Products Marketing, 17(2-3), 327-354.

Cook, M. L., \& Chaddad, F. 2004. Redesigning Cooperative Boundaries: the Emergence of New Models. American Journal of Agricultural Economics, 86(5), 1249-1253.

Deacon, Robert T. 2012. Fishery management by harvester cooperatives. Review of Environmental Economics and Policy, 6(2), 258-277. 
Deller, S., Hoyt, A., Hueth, B., \& Sundaram-Stukel, R. 2009. Research on the Economic Impact of Cooperatives. University of Wisconsin Center for Cooperatives.

Fatas, E., Jimenez-Jimenez, F., \& Morales, A. J. 2010. Blind Fines in Cooperatives. Applied Economic Perspectives and Policy, 32(4), 564-587.

Fischer, E., \& Qaim, M. 2012. Linking Smallholders to Markets: Determinants and Impacts of Farmer Collection Action in Kenya. World Development, 40(6), 1255-1268.

Gale, F. 1997. Direct Farm Marketing as a Rural Development Tool. Rural Development Perspectives, United States Department of Agriculture, 12(2), 19-25.

Giannakas, K., \& Fulton, M. 2005. Process Innovation Activity in a Mixed Oligopoly: The Role of Cooperatives. American Journal of Agricultural Economics, 87(2), 406-422.

Hand, M. S., \& Martinez, S. 2010. Just What Does Local Mean. Choices, 25(1), Available at http://farmdoc.illinois.edu/policy/choices/20101/2010102/2010102.pdf.

Helmberger, P., \& Hoos, S. 1962. Cooperative Enterprise and Organization Theory. Journal of Farm Economics, 44(2), 275-290.

Hendrikse, G. W. J., \& Bijman, J. 2002. On the Emergence of New Growers' Associations: Self-selection versus Market Power. European Review of Agricultural Economics, 29(2), $255-269$.

Hoffmann, R. 2005. Ownership Structure and Endogenous Quality Choice: Cooperative vs Investor Owned Firms. Journal of Agricultural and Food Industrial Organization, 3(2), 1-24.

Holland, S. J., \& King, R. P. 2004. Trading Mechanisms for New Generation Cooperative Stock: the Architecture of Organizational Formation and Demise. American Journal of Agricultural Economics, 86(5), 1262-1268.

Holloway, G., Nicholson, C., Delgado, C., Staal, S., \& Ehui, S. 2000. Agroindustrialization through Institutional Innovation: Transaction Costs, Cooperatives and Milk-market Development in the East-African Highlands. Agricultural Economics, 23(3), 279-288.

Hovelaque, V., Duvaleix-Treguer, S., \& Cordier, J. 2009. Effects of Constrained Supply and Price Contracts on Agricultural Cooperatives. European Journal of Operational Research, 199(3), 769-780.

Jang, W., \& Klein, C. M. 2011. Supply Chain Models for Small Agricultural Enterprises. Annals of Operations Research, 190(1), 359-374.

Karantininis, K., \& Zago, A. 2001. Endogenous Membership in Mixed Duopsonies. American Journal of Agricultural Economics, 83(5), 1266-1272.

Klein, K. K., Richards, T. J., \& Walburger, A. 1997. Determinants of Cooperative patronage in Alberta. Canadian Journal of Agricultural Economics, 45(2), 93-110. 
Ladd, G. W. 1974. A Model of Bargaining Cooperative. American Journal of Agricultural Economics, 56(3), 509-519.

Lopez, R. A., \& Spreen, T. H. 1985. Co-ordination Strategies and Non-members' Trade in Processing Cooperatives. Journal of Agricultural Economics, 36(3), 385-396.

Low, S. A., \& Vogel, S. 2011. Direct and Intermediated Marketing of Local Foods in the United States. ERR - 128, U.S, Department of Agriculture.

Markelova, H., Meinzen-Dick, R., Hellin, J., \& Dohrn, S. 2009. Collective Action for Smallholder Market Access. Food Policy, 34(1), 1-7.

Mujawamariya, G., D'Haese, M., \& Speelman, S. 2013. Exploring Double Side-Selling in Cooperatives, Case Study of Four Coffee Cooperatives in Rwanda. Food Policy, 39(1), $72-83$.

Nourse, E. G. 1922. The Economic Philosophy of Co-operation. American Economic Review, 12(4), 577-597.

Ortmann, G.F., \& King, R. P. 2007. Agricultural Cooperatives I: History, Theory and Problems. Agrekon, 46(1), 40-68.

Pascucci, S., Gardebroek, C., \& Dries, L. 2012. Some Like to Join, Others to Deliver: An Econometric Analysis of Farmers' Relationship with Agricultural Cooperatives. European Review of Agricultural Economics, 39(1), 51-74.

Petraglia, L. M., \& Rogers, R. T. 1999. The Impact of Agriculture Marketing Cooperatives on Market Performance in U.S. Food Manufacturing Industries for 1982. Research Report No. 12, Food Marketing Policy Center, The University of Connecticut.

Roy, D., \& Thorat, A. 2008. Success in High Value Horticultural Export Markets for the Small Farmers: The Case of Mahagrapes in India. World Development, 36(10), 1874-1890.

Royer, J. S., \& Matthey, H. 1999. Optimal Strategies of Marketing Cooperatives Regarding Nonmembers Business. Working Paper. Selected For the 1999 Annual meeting by the American Agricultural Economics Association, August 8-11, Nashville, TN .

Sexton, R. J. 1986. The Formation of Cooperatives: A Game-Theoretical Approach with Implications for Cooperative Finance, Decision Making, and Stability. American Journal of Agricultural Economics, 68(2), 214-225.

Sexton, R. J. 1990. Imperfect Competition in Agricultural Markets and the Role of Cooperatives: A Spatial Analysis. American Journal of Agricultural Economics, 72(3), 709-720.

Sexton, R. J., \& Iskow, J. 1988. Factors Critical to the Success or Failure of Emerging Agricultural Cooperatives. Giannini Foundation Information Series No. 88-3. 
Soboh, R. A. M. E., Lansink, A. O., Giesen, G., \& van Dijk, G. 2009. Performance Measurement of the Agricultural Marketing Cooperatives: The Gap between Theory and Practice. Review of Agricultural Economics, 31(3), 446-469.

Tchami, G. 2007. Handbook on Cooperatives for Use by Worker's Organizations. Geneva: International Labour Office.

Tennbakk, B. 1995. Marketing Cooperatives in Mixed Duopolies. Journal of Agricultural Economics, 46(1), 33-45.

Timmons, D., \& Wang, Q. 2010. Direct Food Sales in the United States: Evidence from State and County-Level Data. Journal of Sustainable Agriculture, 34(2), 229-240.

Uematsu, H., \& Mishra, A. K. 2011. Use of Direct Marketing Strategies by Farmers and their Impact on Farm Business Income. Agricultural and Resource Economics Review, 40(1), $1-19$.

USDA. 2002. Problems and Issues Facing Farmers Cooperatives. Rural Business-Cooperative Service, RBS Research Report 192, United States Department of Agriculture.

USDA. 2004. Farm Marketing, Supply and Service Cooperative Historical Statistics. Cooperative Information Report 1, Section 26, United States Department of Agriculture.

USDA. 2011. Cooperative Statistics, 2010. Service Report 71, United States Department of Agriculture.

Youde, J. G. 1978. Cooperative Membership Policies and Market Power. Agricultural Cooperatives and the Public Interest. North Central Regional Research Project N.C. 117 Studies of the Organization and Control of the U.S. Food System Monograph., 4, 219-225. 


\section{A Proof of Propositions 3.1 and 3.2}

The farmer $i$ 's problem is

$$
\begin{gathered}
\max _{Q_{i}, \theta_{i}}\left\{V_{i}=P_{c} \theta_{i} Q_{i}-A_{i} Q_{i}^{2}+b_{c}\left(P-P_{c}\right) \sum_{j=1}^{N} \theta_{j} Q_{j}\right. \\
\left.+\alpha\left(1-\theta_{i}\right) Q_{i}-\beta\left(1-\theta_{i}\right) Q_{i} \sum_{j=1}^{N}\left(1-\theta_{j}\right) Q_{j}\right\} .
\end{gathered}
$$

Writing the first-order condition with respect to $\theta_{i}$ and simplifying by $Q_{i}$ yields

$$
P_{c}+b_{c}\left(P-P_{c}\right)-\alpha+\beta\left[\sum_{j=1}^{N}\left(1-\theta_{j}\right) Q_{j}+\left(1-\theta_{i}\right) Q_{i}\right]=0 .
$$

From 115$),\left(1-\theta_{i}\right) Q_{i}=\frac{\alpha-b_{c} P-\left(1-b_{c}\right) P_{c}}{\beta}-\sum_{j=1}^{N}\left(1-\theta_{j}\right) Q_{j}$

Considering equation 16 for each producer, we have

$$
\begin{gathered}
\left(1-\theta_{1}\right) Q_{1}=\left(1-\theta_{2}\right) Q_{2}=\cdots=\left(1-\theta_{N}\right) Q_{N} \\
\text { Therefore equation (16) gives } Q_{i}=\frac{\alpha-b_{c} P-\left(1-b_{c}\right) P_{c}}{\beta(N+1)\left(1-\theta_{i}\right)} .
\end{gathered}
$$

The first-order condition with respect to $Q_{i}$ is

$$
\begin{array}{r}
P_{c} \theta_{i}-2 A_{i} Q_{i}+b_{c}\left(P-P_{c}\right) \theta_{i}+\alpha\left(1-\theta_{i}\right) \\
-\beta\left[\left(1-\theta_{i}\right) \sum_{j=1}^{N}\left(1-\theta_{j}\right) Q_{j}+\left(1-\theta_{i}\right)^{2} Q_{i}\right]=0 .
\end{array}
$$

Or $P_{c} \theta_{i}-P_{c}+P_{c}-2 A_{i} Q_{i}+b_{c}\left(P-P_{c}\right) \theta_{i}-b_{c}\left(P-P_{c}\right)+b_{c}\left(P-P_{c}\right)$

$$
+\alpha\left(1-\theta_{i}\right)-\beta\left[\left(1-\theta_{i}\right) \sum_{j=1}^{N}\left(1-\theta_{j}\right) Q_{j}+\left(1-\theta_{i}\right)^{2} Q_{i}\right]=0 .
$$

So, $P_{c}-\left(1-\theta_{i}\right) P_{c}-2 A_{i} Q_{i}+b_{c}\left(P-P_{c}\right)-b_{c}\left(P-P_{c}\right)\left(1-\theta_{i}\right)$

$$
+\alpha\left(1-\theta_{i}\right)-\beta\left(1-\theta_{i}\right)\left[\sum_{j=1}^{N}\left(1-\theta_{j}\right) Q_{j}+\left(1-\theta_{i}\right) Q_{i}\right]=0 .
$$




$$
\text { Let } K \equiv \frac{\alpha-b_{c} P-\left(1-b_{c}\right) P_{c}}{\beta(N+1)} ; S o, \forall j=1, \cdots, N,\left(1-\theta_{j}\right) Q_{j}=K \text {. }
$$

Rearranging (21) and using 222, we find

$$
1-\theta_{i}=\frac{2 A_{i} K}{b_{c} P+\left(1-b_{c}\right) P_{c}} .
$$

Let us turn now to the cooperative's problem which is

$$
\max _{P_{c}} \Pi_{c}=\left(P-P_{c}\right) \sum_{j=1}^{N} \theta_{j} Q_{j}
$$

Using (18), 222, and (23), one can find that

$$
\sum_{j=1}^{N} \theta_{j} Q_{j}=\left(b_{c} P+\left(1-b_{c}\right) P_{c}\right) \sum_{j=1}^{N} \frac{1}{2 A_{i}}-N K .
$$

The problem of the cooperative becomes

$$
\max _{P_{c}} \Pi_{c}=\left(P-P_{c}\right)\left(\left(b_{c} P+\left(1-b_{c}\right) P_{c}\right) \sum_{j=1}^{N} \frac{1}{2 A_{i}}-N K\right) .
$$

Deriving the first-order condition yields the expected results for $P_{c}^{*}$ and $Q_{i}^{*}{ }^{21}$

\section{B Proof of Proposition 3.3}

From (22) and (23) we have $1-\theta_{i}=\frac{2 A_{i}}{\beta(N+1)}\left[\frac{\alpha}{b_{c} P+\left(1-b_{c}\right) P_{c}}-1\right]$ We find the result by plugging the expression of $P_{c}$ into the expression above for $1-\theta_{i}$, and taking account of the fact that $\theta_{i}$ has to be between 0 and 1 .

\section{Proof of Proposition 4.1}

The problem of the farmer $i$ is

$$
\begin{gathered}
\max _{Q_{i}, \theta_{i}}\left\{V_{i}=P_{c} \theta_{i} Q_{i}-A_{i} Q_{i}^{2}+b_{c}\left(P-P_{c}\right) \sum_{j=1}^{N} \theta_{j} Q_{j}\right. \\
\left.+\alpha\left(1-\theta_{i}\right) Q_{i}-\beta\left(1-\theta_{i}\right) Q_{i} \sum_{j=1}^{N}\left(1-\theta_{j}\right) Q_{j}\right\},
\end{gathered}
$$

subject to the constraint $0 \leq \theta_{i} \leq 1$. If $\frac{\alpha}{P}<\bar{\alpha}_{i}$ for all $i$, then the constraint $\theta_{i} \geq 0$ is not bounded. From Equation (22) we find the result.

\footnotetext{
${ }^{21}$ The second-order condition confirms these results.
} 


\section{Proof of Proposition 4.4}

The profit made by the farmer $i$ on the local market is $V_{i}^{D}=P^{D}\left(1-\theta_{i}\right) Q_{i}^{*}-\left(1-\theta_{i}\right) A_{i}\left(Q_{i}^{*}\right)^{2}{ }^{22}$ We can write $V_{i}^{D}=(\alpha-N \beta K) K-A_{i} K Q_{i}^{*}$. Using (18), 222) and (23), we can find that $Q_{i}^{*}=$ $\frac{b_{c} P+\left(1-b_{c}\right) P_{c}}{2 A_{i}}=\frac{\alpha-\beta(N+1) K}{2 A_{i}}$. We can rewrite and rearrange $V_{i}^{D}$ as $V_{i}^{D}=\frac{1}{2}\left(\alpha K-(N-1) \beta K^{2}\right)$. We can then calculate the first derivative of $V_{i}^{D}$ with respect to $K$ and get to the result.

\section{E $\quad$ Proof of Proposition 4.3}

If $A_{j}=A, \forall j$, then $\sum_{j=1}^{N} Q_{j}^{*}=\frac{N \alpha}{4 A+2 \beta(N+1)}+\frac{N P}{4 A}$ and $\sum_{j=1}^{N} q_{j}^{o}=\frac{N \alpha}{2 A+\beta(N+1)}$. We can then compare $\sum_{j=1}^{N} Q_{j}^{*}$ and $\sum_{j=1}^{N} q_{j}^{o}$.

\section{F Proof of Proposition 4.2}

We assume that $A_{j}=A, \forall j$. Basing on Proposition 3.3, we distinguish three cases. If $\frac{\alpha}{P} \leq \underline{\alpha}=\frac{2 A+\beta(N+1)}{2 A+2 \beta(N+1)}$ then $1-\theta_{j}=0$ for all $j$ and we get to the result. If $\frac{\alpha}{P} \geq \bar{\alpha}=\frac{2 A+\beta(N+1)}{2 A}$ then $1-\theta_{j}=1$ for all $j$, and $\sum_{j=1}^{N}\left(1-\theta_{j}\right) Q_{j}^{*}=\sum_{j=1}^{N} Q_{j}^{*} \leq \sum_{j=1}^{N} q_{j}^{o}$, from Proposition 4.3 . If $\underline{\alpha}<\frac{\alpha}{P}<\bar{\alpha}$ then $\sum_{j=1}^{N}\left(1-\theta_{j}\right) Q_{j}^{*}-\sum_{j=1}^{N} q_{j}^{o}=\frac{N \alpha(2 A+2 \beta(N+1))}{\beta(N+1)(4 A+2 \beta(N+1)}-\frac{N P}{2 \beta(N+1)}-\frac{N \alpha}{2 A+\beta(N+1)}=$ $\frac{N}{2 \beta(N+1)}\left[\frac{2 A \alpha}{2 A+\beta(N+1)}-P\right]<0$.

\section{G Cooperative with capacity constraint}

In this paper, we assume that the cooperative accepts to purchase the entire quantity of products the farmers decide to sell. However, sometimes, the cooperative is subject to a capacity constraint (defective storage facilities, governmental quotas, etc.) and cannot buy the whole volume for sale. The capacity constraint $\bar{K}$ is exogeneous and known by the cooperative members. For example, it is the case of harvesters cooperatives who manage collective fishing quotas (Deacon, 2012). Proposition G.1 reexamines Proposition 4.1 within the context of restriction implied by capacity constraint.

Proposition G.1. If the cooperative has a capacity constraint, then the farmers do not necessary sell the same quantity on the local market, as seen in Proposition 4.1.

Proof. Let us denote by $\bar{K}$ the maximal amount of products the cooperative can buy from the

\footnotetext{
${ }^{22}$ We assume that the production cost is shared over the local market and the large market proportionally to the percentage of production sold on each market. This way to share cost is inspired by Karantininis \& Zago (2001).
} 
farmers. The farmer $i$ 's problem is

$$
\begin{aligned}
& \max _{Q_{i}, \theta_{i}}\left\{V_{i}=P_{c} \theta_{i} Q_{i}-A_{i} Q_{i}^{2}+b_{c}\left(P-P_{c}\right) \sum_{j=1}^{N} \theta_{j} Q_{j}\right. \\
& \left.+\alpha\left(1-\theta_{i}\right) Q_{i}-\beta\left(1-\theta_{i}\right) Q_{i} \sum_{j=1}^{N}\left(1-\theta_{j}\right) Q_{j}\right\} \\
& \text { subject to } \sum_{j=1}^{N} \theta_{j} Q_{j} \leq \bar{K} .
\end{aligned}
$$

Writing the first-order condition with respect to $\theta_{i}$ and simplifying by $Q_{i}$ yields

$$
P_{c}+b_{c}\left(P-P_{c}\right)-\alpha+\beta\left[\sum_{j=1}^{N}\left(1-\theta_{j}\right) Q_{j}+\left(1-\theta_{i}\right) Q_{i}\right]-\lambda_{i}=0,
$$

where $\lambda_{i} \geq 0$ is the Lagrange multiplier corresponding to the capacity constraint for the problem in equation (28).

$$
\text { From } 29], \beta\left(1-\theta_{i}\right) Q_{i}-\lambda_{i}=\alpha-b_{c} P-\left(1-b_{c}\right) P_{c}-\beta \sum_{j=1}^{N}\left(1-\theta_{j}\right) Q_{j}
$$

Considering equation 30 for each producer, we have

$$
\left(1-\theta_{1}\right) Q_{1}-\frac{\lambda_{1}}{\beta}=\left(1-\theta_{2}\right) Q_{2}-\frac{\lambda_{2}}{\beta}=\cdots=\left(1-\theta_{N}\right) Q_{N}-\frac{\lambda_{N}}{\beta} .
$$

From (31), if the capacity constraint is not bounded, then the farmers sell an equal quantity on the local market. Assume now that the capacity constraint is bounded $\left(\sum_{j=1}^{N} \theta_{j} Q_{j}=\bar{K}\right)$. The first-order condition with respect to $Q_{i}$ is

$$
\begin{array}{r}
P_{c} \theta_{i}-2 A_{i} Q_{i}+b_{c}\left(P-P_{c}\right) \theta_{i}+\alpha\left(1-\theta_{i}\right) \\
-\beta\left[\left(1-\theta_{i}\right) \sum_{j=1}^{N}\left(1-\theta_{j}\right) Q_{j}+\left(1-\theta_{i}\right)^{2} Q_{i}\right]-\lambda_{i} \theta_{i}=0 .
\end{array}
$$

From 29), $\lambda_{i}=P_{c}+b_{c}\left(P-P_{c}\right)-\alpha+\beta\left[\sum_{j=1}^{N}\left(1-\theta_{j}\right) Q_{j}+\left(1-\theta_{i}\right) Q_{i}\right]$. Therefore, 32 becomes

$$
2 A_{i} Q_{i}+\beta\left(1-\theta_{i}\right) Q_{i}=\alpha-\beta \sum_{j=1}^{N}\left(1-\theta_{j}\right) Q_{j}
$$

Considering $(33)$ for each farmer, we get to

$$
\left(1-\theta_{1}\right) Q_{1}+\frac{2 A_{1} Q_{1}}{\beta}=\left(1-\theta_{2}\right) Q_{2}+\frac{2 A_{2} Q_{2}}{\beta}=\cdots=\left(1-\theta_{N}\right) Q_{N}+\frac{2 A_{N} Q_{N}}{\beta} .
$$


We now need to prove that the $A_{j} Q_{j}$ may vary with $j$ when there is capacity constraint. An example is the case of direct selling with no marketing cooperative $(\bar{K}=0)$ studied in Section 2.2,

If there is an increase of $\bar{K}$ then the $\lambda_{j} s$ will decrease $\left(\lambda_{i}\right.$ is the shadow price of the cooperative's capacity for farmer $i$ ). Therefore, due 29$)$, the quantity $\sum_{j=1}^{N}\left(1-\theta_{j}\right) Q_{j}+$ $\left(1-\theta_{i}\right) Q_{i}$ will decrease, which means the farmers will decrease their sales amount on the local market.

\section{H Figures}
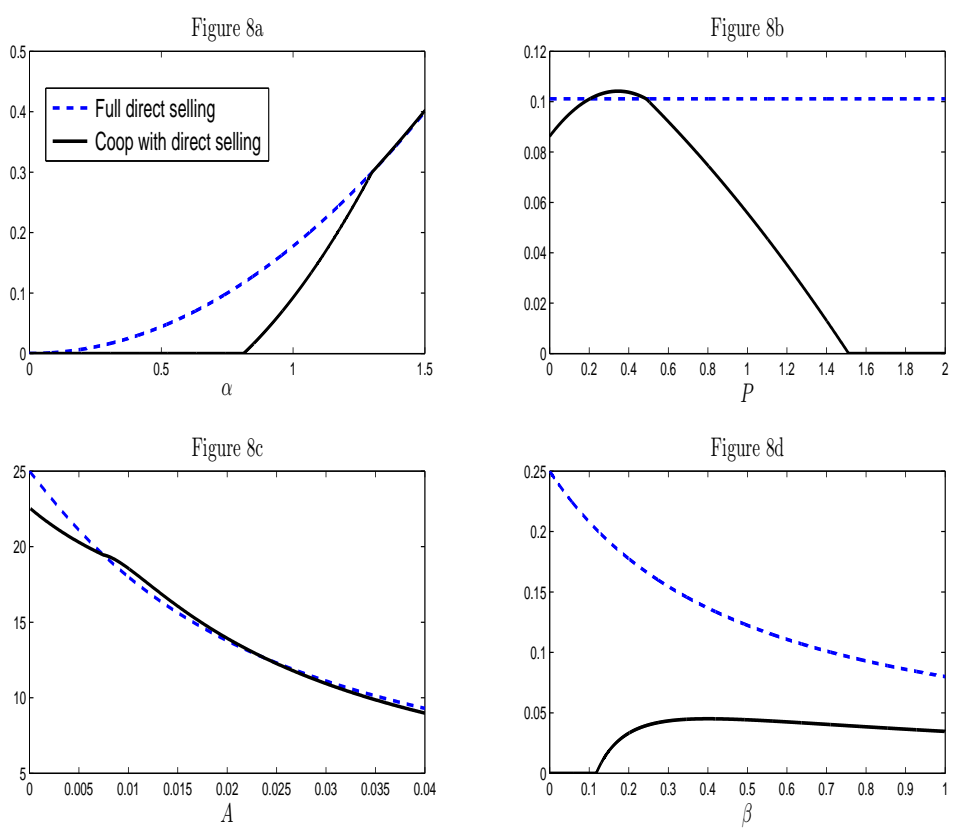

Figure 8: Farmers' individual profits made on local market. For Figure 8a, we set $N=2, A_{i}=1$ $\forall i, P=1, \beta=0.2$, and $b_{c}=\frac{1}{N+1}$. For Figure 8b, $N=2, A_{i}=1 \forall i, \alpha=1, \beta=0.7$, and $b_{c}=\frac{1}{N+1}$. For Figure $8 \mathrm{c}, N=2, P=0.5, \alpha=1.5, \beta=0.01$, and $b_{c}=\frac{1}{N+1}$. For Figure $8 \mathrm{~d}, N=2, A_{i}=1 \forall i$, $\alpha=1, P=1.15$, and $b_{c}=\frac{1}{N+1}$ 


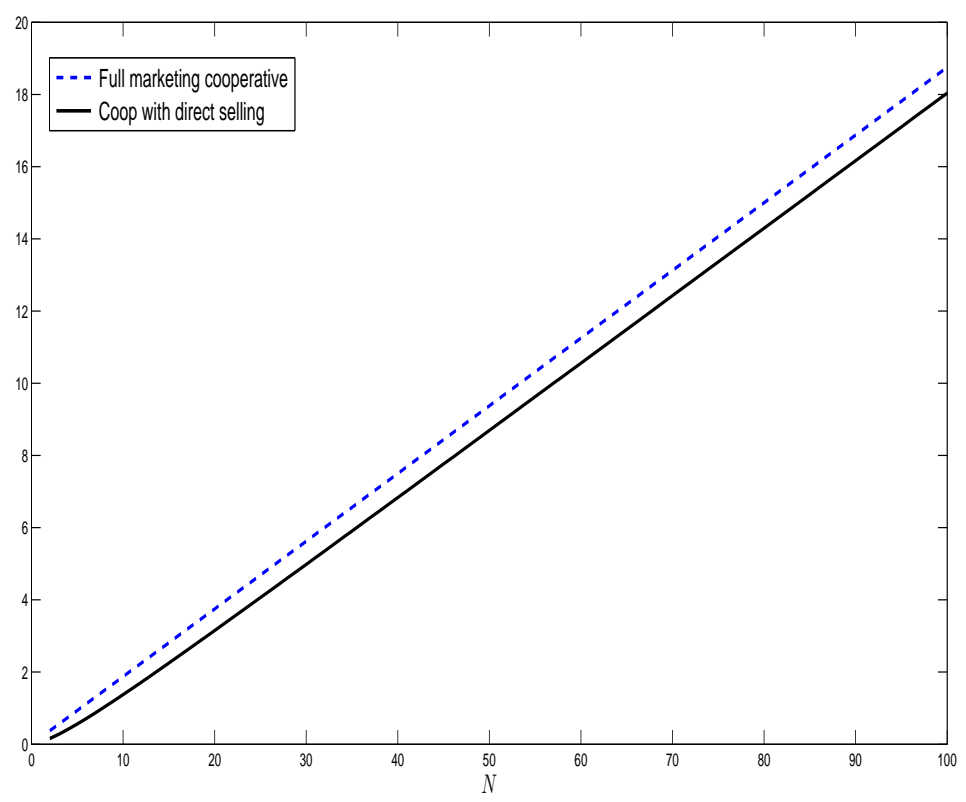

Figure 9: The profits made by the cooperative. We set $P=1, A_{i}=1 \forall i, \alpha=1, \beta=0.5$, and $b_{c}=\frac{1}{N+1}$.
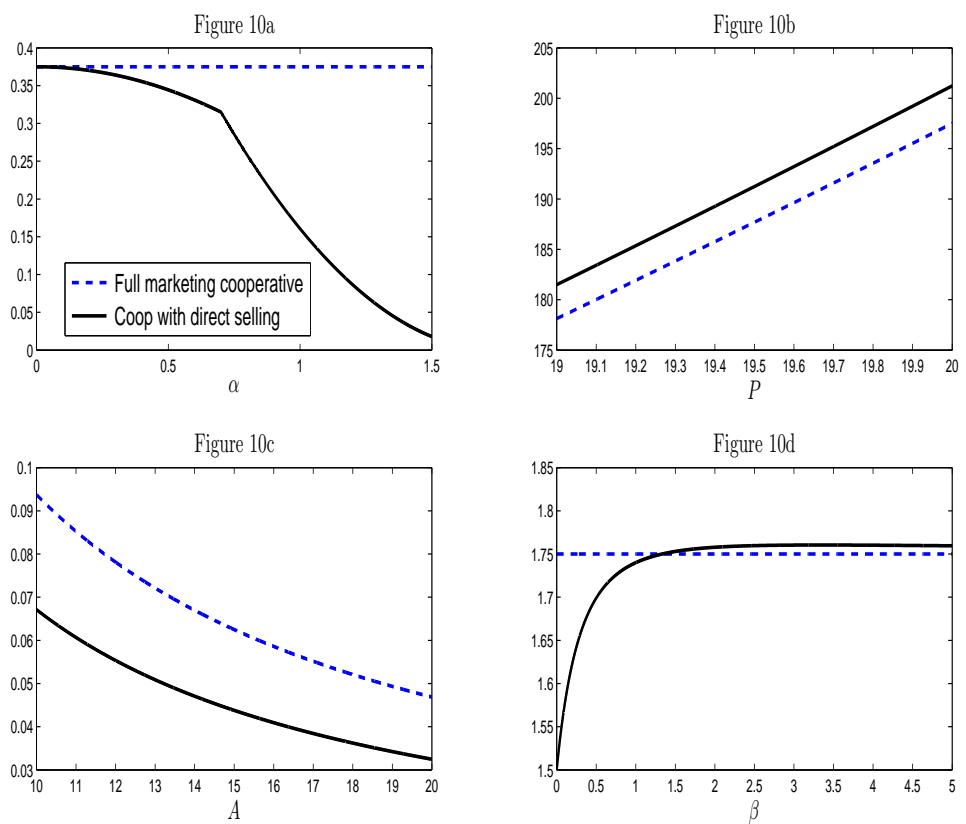

Figure 10: The profits made by the cooperative. For Figure 10a, we set $N=2, A_{i}=1 \forall i, P=1$, $\beta=0.5$, and $b_{c}=\frac{1}{N+1}$. For Figure 10b, $N=2, A_{i}=1 \forall i, \alpha=5, \beta=0.5$, and $b_{c}=\frac{1}{N+1}$. For Figure $10 \mathrm{c}, N=2, P=1.5, \alpha=1, \beta=0.5$, and $b_{c}=\frac{1}{N+1}$. For Figure 10d, $N=2, A_{i}=1 \forall i, \alpha=1, P=2$, and $b_{c}=\frac{1}{N+1}$ 